\title{
Mapping Sabkha Land Surfaces in the United Arab Emirates (UAE) using Landsat 8 Data, Principal Component Analysis and Soil Salinity Information
}

\author{
Abdelgadir Abuelgasim ${ }^{\mathrm{a}}$, Rubab Ammad ${ }^{\mathrm{b}}$ \\ ${ }^{a}$ Department of Geography and Urban Planning, College of Humanities and Social Sciences, United Arab \\ Emirates University, Al-Ain, Abu Dhabi 15551, UAE \\ ${ }^{b}$ Department of Biology, College of Science, United Arab Emirates University, Al-Ain, Abu Dhabi 15551, UAE
}

\begin{abstract}
Sabkha is an Arabic word for a salt-flat area found mainly along arid area coastlines and inlands within sand dunes areas. The sabkha that form within the sand are relatively flat and very saline areas of sand or silt that forms just above the water-table where the sand is cemented together by evaporite salts from seasonal ponds. Such shallow water is normally highly saline. Here the crust is rich in gypsum and halite veins where the underline thin layer is made of sand and silt. Such sabkha have an average thickness of a meter or slightly less. On the other hand, marine sabkha represent transitional environments between the land and the sea. The UAE is home to some of the largest concentrations of sabkha both coastal and inland. The coastal areas of Abu Dhabi include several small shoals, islands, protected lagoons, channels and deltas, an inner zone of intertidal flats with algal mats and broad areas of supratidal sabkha salt flats.

Identifying sabkha habitats from remotely sensed data is a challenging process. Traditional classification techniques of multispectral data alone, usually fail to properly identify sabkha pixels or provide lower rates of mapping accuracy for sabkha habitats. The primary objective of this research is to develop a much more accurate methodology for properly mapping and identifying sabkha areas from remotely sensed data. Properly mapping sabkha habitats from remotely sensed data is the first steps towards studying the ecological changes within such habitats using earth observation techniques. Furthermore, sabkha habitats can in certain situations be a geotechnical hazard due to its highly salinity and with adverse effects on concrete, asphalt, steel and other structures, in addition to their sporadic heaves and collapses. As the UAE continue to build major infrastructure and development projects identifying the location of such habitats is vitally important.

In this research a new technique that combines the multispectral information of Landsat 8, principal component analysis and spectral soil salinity detection is developed. The study area is located in the western part of the UAE along the border with the Kingdom of Saudi Arabia, an area known to include large tracks of inland and coastal sabkha. Landsat 8 data from path 161 and row 43 was acquired for the study. A multi-source classification approach was followed that utilizes the multispectral data of Landsat 8 along with components from the principal components analysis and the spectral salinity index maps. The preliminary results confirmed

\footnotetext{
* Corresponding author. Tel.:

E-mail address:
} 
by field observations show that the combined data improved the classification accuracy to almost $90 \%$ in comparison to multispectral data alone of $78 \%$.

Index Terms: Sabkha, Landsat 8, UAE.

(C) 2017 Published by MECS Publisher. Selection and/or peer review under responsibility of the Research Association of Modern Education and Computer Science.

\section{Introduction}

Sabkha are salt flats associated with hot and arid climate, typically formed in shallow continental shelf/ marine environment [1]. They are classified as inland sabkha, present within the sand dunes, or coastal sabkha, found on shoreline and distinguished based on formation in varying tidal environments: 1) sub-tidal flats, 2) lagoons and intertidal flats, 3) supratidal flats [2,3]. Inland sabkha that form within the sand dune areas are relatively flat and highly saline areas of sand or silt formed just above the water-table where the sand is cemented together by evaporite salts from seasonal ponds. Coastal sabkha are characterized by evaporite deposits, which may consist of carbonates or siliciclastics.

Sabkha habitats are under constant threat in the UAE because of rapid economic development, major urbanization projects, increased population, and environmental pollution. In the last 30 years in the UAE, such habitats have been significantly negatively affected and remain under constant pressures from anthropogenic activities.

The primary objective of this research study is to develop a new technique for mapping inland sabkha habitats using multispectral remotely sensed data. Identifying sabkha pixels in remotely sensed images has been quite a difficult process [4]. This is primarily due to the confusion of sabkha pixels with saline soils and the mixture of sabkha with sand dunes making spectral separation a challenging process. This research uses the multispectral information provided by Landsat 8 data in addition to a set of transformed multispectral data including principal components and a salinity index to accurately identify sabkha pixels from other land cover pixel types.

\section{Study Area}

The study area represents the western parts of the city of Abu Dhabi and the western extremities of the UAE. This area in particular is home to some of the largest sabkha habitats in the world. It includes both coastal sabkha and inland sabkha that can be found within proximity of tens of kilometers from the coast. The study uses Landsat 8 multispectral data, path 161 and row 43, collected on July 15th 2015which comprises of spectral bands from 2-7. It was deemed unnecessary to use Landsat 8 band 1 as the focus of the study is on the inland sabkha rather than the coastal sabkha.

\subsection{Climatology}

The climate of the area is hot, dry and arid with scarce amount of annual rainfall around $72 \mathrm{~mm}$ [5] and rates of evaporation exceeding $2000 \mathrm{~mm}$ per year [6]. This high evaporation rate accounts for salinities ranging from $37 \%$ near Strait of Hormuz and 65\% in the Arabian coastal lagoons [7, 8] whereas in shallow depths of UAE coastal areas the average salinities vary from $40-50 \%$ and in lagoons and embayments they can reach up to 60 $70 \%$ [1]. The temperature $25 \mathrm{~cm}$ below the sabkha go up to $17^{\circ} \mathrm{C}$ in winters and $43^{\circ} \mathrm{C}$ in summers respectively [9]. Shamal wind is the prominent climatic feature of the area, which blows in north-west direction. Storm outbreaks result in shallow inundation of the coastal area due to ramp geometry of coastline. 


\subsection{Geologic setting of sabkha}

Main contributors to sabkha formation in the study area are the eustatic sea levels, in the late Quaternery [10] and north (Shamal) winds and currents, which resulted in erosion of Pleistocene sand dunes some 7000 years ago [1]. On northern coast of UAE, Sabkha emerged as a product of global sea-transgression and regression cycles during the latter part of Pleistocene time. About 12000-10000 years ago, [11, 12], sea level began to rise reaching a little above its present level around 4000 years ago, meanwhile flooding the depressions between coastline and dessert sand dunes.

Salt flats and depressions formed at the time of this fluctuating sea level and simultaneous erosion of late Quaternary [13]. Carbonates deposited on the seabed during phases of flooding and shrivel, once the water retreated. Carbonate sand dunes evolved as the strong winds blew following the transgression-regression cycles. High evaporation rates caused the soil to become salt-concentrated, which eventually lead to formation of a halite crust that expanded laterally as it desiccated and retained the shape of polygon, uplifting the margins. Fluids inside the sediments crystalized gypsum as they saturated with calcium sulphate. [2,14] have described the evolution of sabkha in the study area in 6 phases, based on different tidal environments including subtidal flats (khors) and intertidal channels, lagoons (intertidal flats) and supratidal flats [2] .

Coastal sabkha run for about $24 \mathrm{~km}$ inland between Abu Dhabi and Umm al Qawain and Sabkha Matti, the largest sabkha, extends for $150 \mathrm{~km}$ in the northern Rubal Khali Desert [15]. These inland sabkha exist in form of secluded interdunal plains, that flood during heavy rainfall and are characterized by intertwined polyhedrons of sand and gypsum [16]. Coastal sabkha are dominated by carbonate sands, contrary to inland sabkha which are siliclastic in nature [8].

\subsection{Studying sabkha through remote sensing}

Sabkha, as described earlier, develop in response to high evaporation rates, which result in supersaturation of soils with insoluble salts [17]. This associated soil salinity is used for identifying sabkha through remotely sensed data; either directly by recognizing exposed salt topographies or indirectly by pinpointing the vegetation related to saline soils. Multispectral satellite imagery is the most commonly used and conveniently available technique for mapping saline soils [4] in which maximum effectiveness is achieved with less than 5m pixel size [18]. In addition to multispectral sensors, there is also a more sophisticated alternative available for mapping the saline soils, in form of hyperspectral sensors. These sensors have better spatial and spectral resolution compared to multispectral sensors and they are able to capture variations in salinities much more comprehensively.

It is significant to note that salt reflectance is dependent on a number of factors such as salt type, mineralogy, color, and surface roughness [19]. Usually, the more the amount of salt in soil the higher is the reflectance and vice versa. Spectral sensitivity of highly saline soils lies in the range of visible and near-infrared part of spectrum and hence the salt features can be interpreted through multispectral data using this knowledge. Similarly, to differentiate between the salt mineralogy, thermal bands in the electromagnetic spectrum are used [4]. [20] used VNIR (visible and near-infrared) spectrum to distinguish between sabkha sands, beach sands and aeolian dune sands, and concluded that sabkha sands, mainly composed of quartz, gypsum and salts, show low (20-30\%) TM reflectance in visible and near infrared (1-4 bands) but increased reflectance in band 5 in the near infrared.

\section{Methodology, Results and Discussions}

The first step in the image processing was to perform the atmospheric correction for the Landsat 8 data. The FLAASH program in ENVI that utilizes the MODTRAN atmospheric correction algorithm was used for the 
correction of the data. The atmospherically corrected image was classified using an unsupervised classification approach. The identification of the resulting spectral clusters to land cover classes was done through field work and land cover maps of the area. Nine land cover types were identified in the scene of which water classes and the zero pixels made four of them. The resulting land cover types represented the variations in the different desert surfaces soil types, urban structures, and sabkha. Fig. 1 shows the resulting classification map.

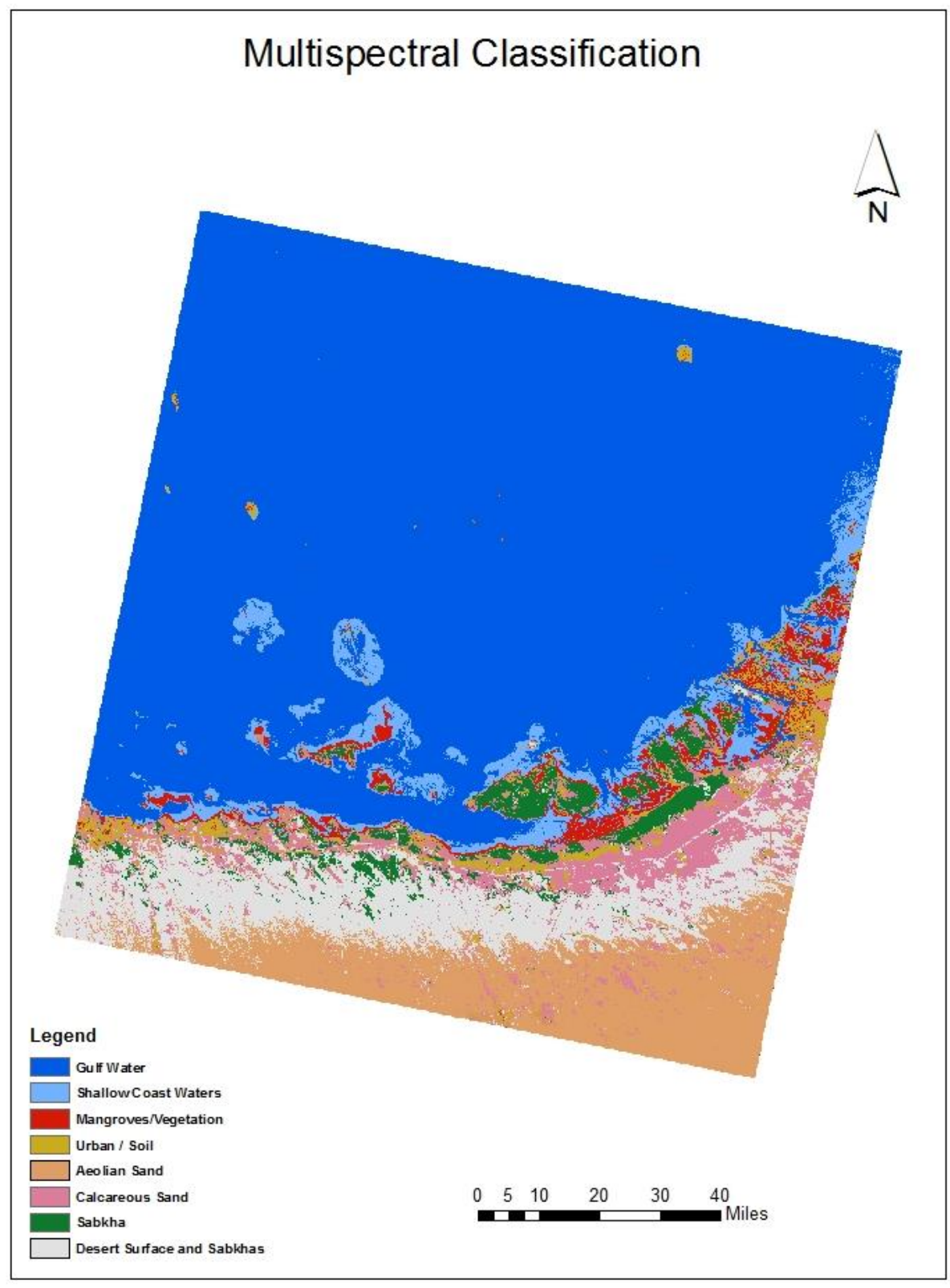

Fig.1. Land Cover Classification 
The resulting classification shows strong confusion between the pixels of sabkha and sand surfaces [21]. The desert surface class shown in grey in the map encompasses pixels of sand surface as well as sabkha pixels. It is not easy to spectrally separate sabkha pixels from sand desert surfaces. To improve the separability of sabkha pixels from other classes a principal component analysis was performed on the multispectral data of the Landsat 8 data. Six components resulting from the transformation were carefully analyzed to identify if any of the components was particularly portraying sabkha pixels in comparison to other land cover types. The analysis was done through visual interpretation of the images and the analysis of the transformation eigenvectors. The resulting transformation eigenvectors of covariance matrix as shown in Table 1.

Table 1. Eigenvectors of the Covariance Matrix of the Principal Component Transformation

\begin{tabular}{|c|c|c|c|c|c|c|}
\hline & Band 2 & Band 3 & Band 4 & Band 5 & Band 6 & Band 7 \\
\hline PC1 & 0.20 & 0.29 & 0.38 & 0.46 & 0.55 & 0.46 \\
\hline PC2 & 0.53 & 0.53 & 0.29 & 0.08 & -0.35 & -0.47 \\
\hline PC3 & -0.38 & -0.24 & 0.11 & 0.73 & -0.01 & -0.50 \\
\hline PC4 & 0.57 & -0.24 & -0.53 & 0.09 & 0.48 & -0.31 \\
\hline PC5 & 0.30 & -0.18 & -0.32 & 0.46 & -0.58 & 0.47 \\
\hline PC6 & -0.35 & 0.69 & -0.61 & 0.15 & 0.06 & 0.00 \\
\hline
\end{tabular}

Of particular importance and relevance were components 1 and component 6 . The first component represented the overall scene brightness. Desert surface appear bright, with varying levels of brightness among the different desert surfaces and water bodies appeared darker in comparison to desert surfaces. Previously knowledge of the exact location of certain sabkha helped the interpretation of principal component 6 . Component 6 showed sabkha pixels in extremely darker tones in comparison to any other land cover type, which suggests that this component is strongly related to the presence of sabkha at these pixels. As expected the sabkha pixels in component 6 showed high levels of brightness in component due to the brighter nature of the salt body within these pixels. Fig. 2 and 3 show the two principal components.

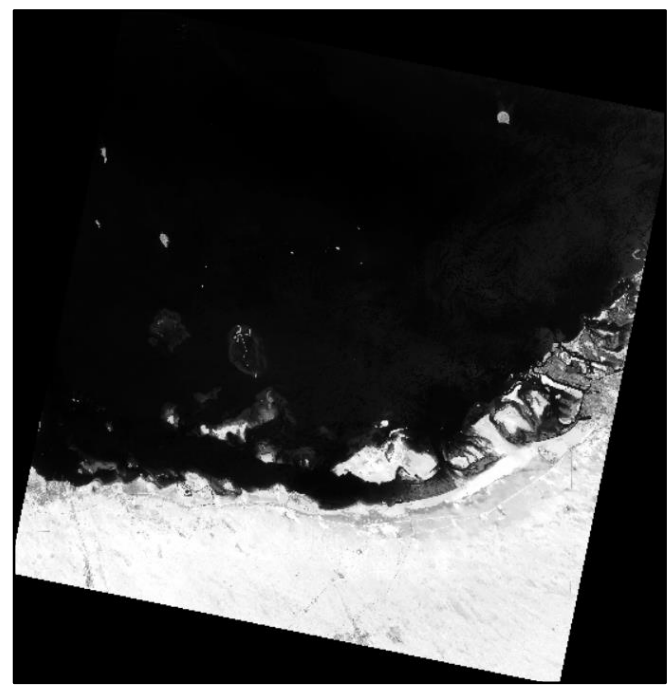

Fig.2. Principal Component 1 


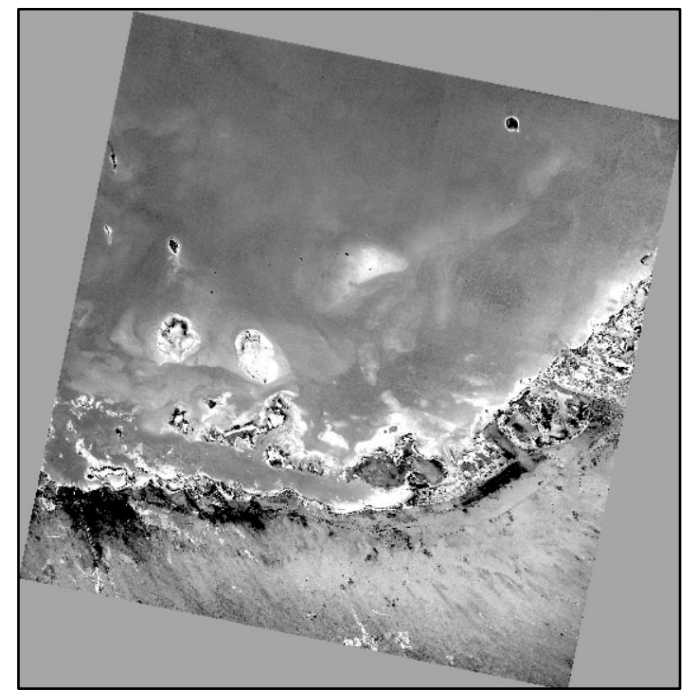

Fig.3. Principal Component 6

Principal component 6 carries high loading factors for spectral bands 3 and 4 of Landsat 8 . This suggests strong correlation between the reflected radiation in the green and red parts of electromagnetic spectrum and the presence of sabkha or saline areas [22]. A sabkha index can be developed from this relation that takes into account the sabkha reflectance in the green and red parts of the spectrum. High index values suggest strong presence of sabkha. It is necessary to apply a threshold to separate high values from non sabkha index values. The developed index took the form of

\section{Sabkha Index = Green Reflectance/Red Reflectance}

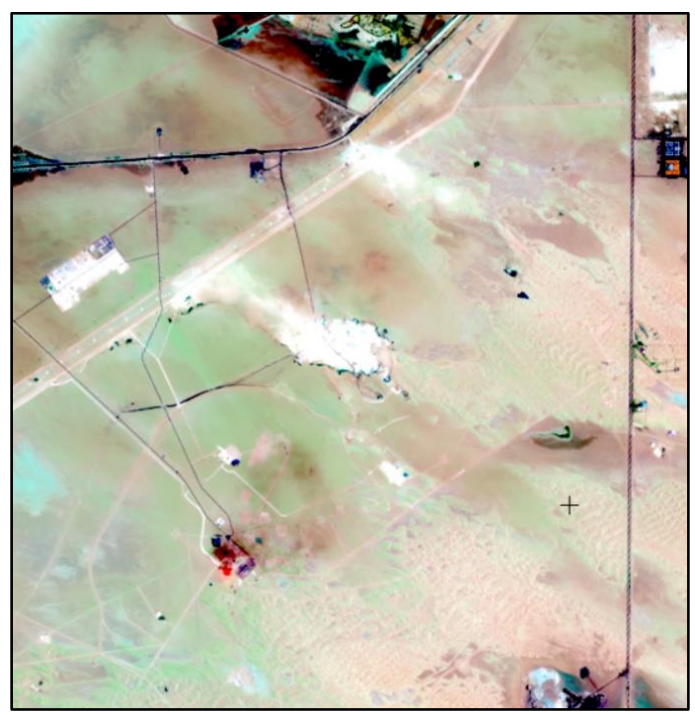

Fig.4. Sabkha Area (bright white pixels) 


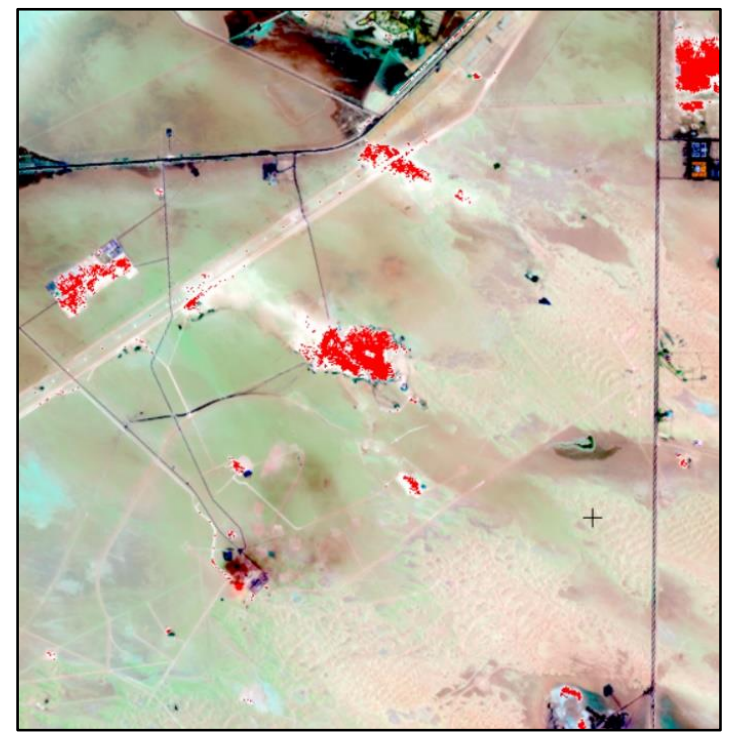

Fig.5. High Sabkha Index Values Shown in Red

The index calculation was applied for a selected area of the image with known discrete sabkha as shown in Fig. 4. Fig. 5., shows the index high values associated with sabkha pixels shown in red. There is a strong agreement between the two images where most sabkha in Fig. 4. are properly identified in Fig. 5 as red pixels. The missing pixels not identified as sabkha in Fig. 5. are due to the threshold cutoff point.

Image transformation processes such as principal component analysis and spectral indices development helps to identify patterns in the data that would not be obvious from the analysis of the multispectral data only. Image transformation processes help transform the original bands into "new" images which better display or highlight certain features in the scene. To improve the separability of sabkha pixels from pixels of other land cover types the multispectral data of Landsat 8 was combined with the two principal components (component 1 and 6) along with a sabkha index image. The resulting dataset represented the full multispectral Landsat 8 dataset along with the transformed multispectral data and is thought to have better abilities in separating sabkha pixels from other land cover classes.

An unsupervised classification process was applied to the new dataset. The dataset has 9 inputs representing the 6 Landsat 8 reflective bands, the two principal components and the sabkha index layer. The resulting classification is shown is Fig. 6.

Using the new dataset for classification resulted in significantly improved identification and separation of sabkha areas from other land cover types. One key noticeable improvement can be seen in the comparison between Fig. 1. and Fig. 6. Using the new data set it was able to separate the sabkha areas from the desert surface class in which they were mistakenly classified using multispectral dataset only. The confusion between sabkha and desert surfaces was predominantly on the two major desert surfaces of aeolian and calcareous sands, with the confusion with the latter being more prominent. Furthermore, the combined dataset helped in separating sabkha from saline soils. 


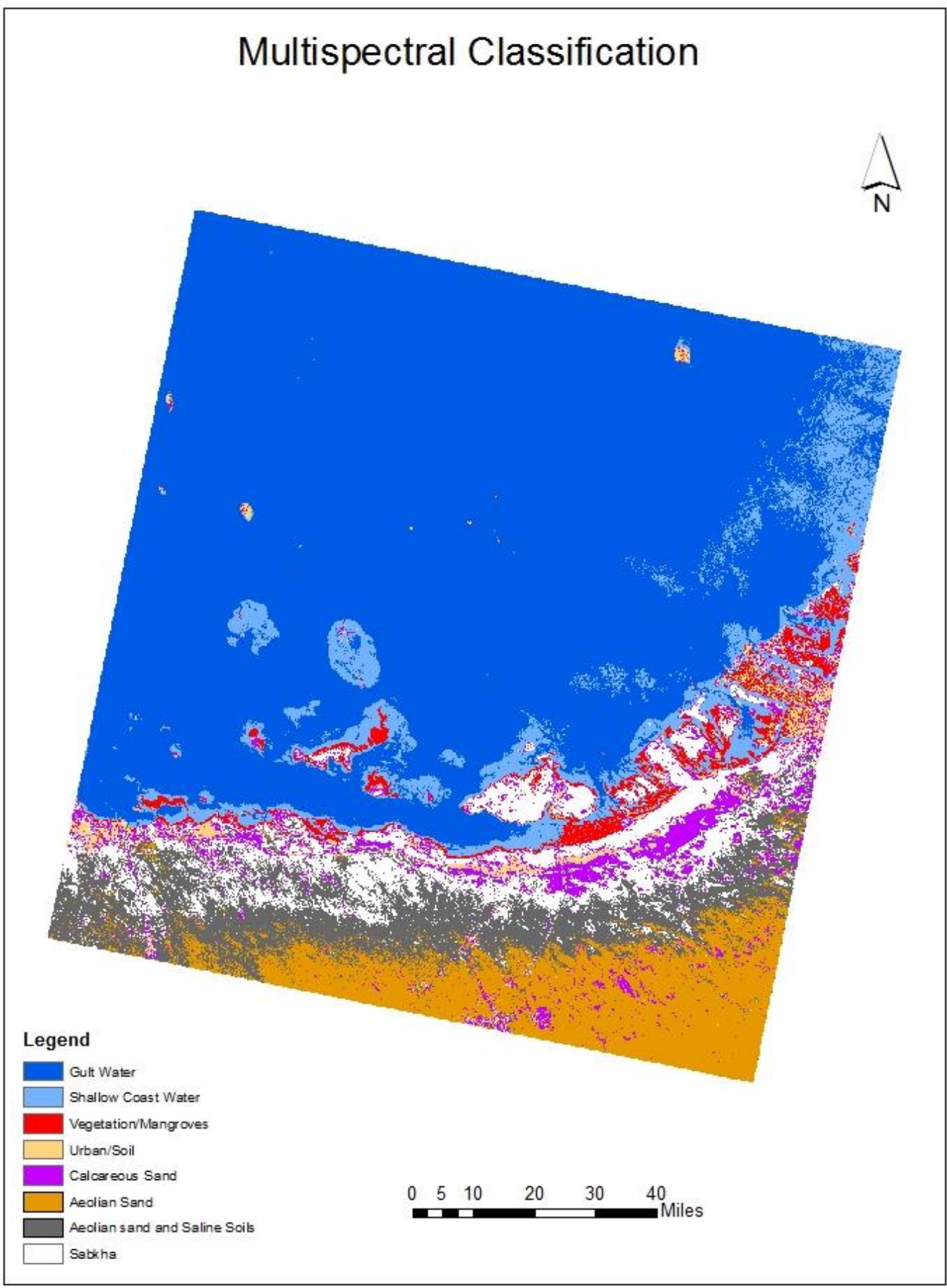

Fig.6. Land Cover Classification using Multispectral and Index Dataset 
To assess the accuracy of the two maps a field campaign was organized. The field survey was focused on assessing the accuracy of using the two mapping datasets. Forty points were selected prior to conducting the field visit. Field observations included recording the exact geographic location of each point and describing the land cover of each point. In the first map that used only the multispectral dataset 31 points were correctly classified representing an overall $78 \%$ accuracy in mapping sabkha areas. In this map 9 point were wrongly classified. For the second map that used dataset of multispectral, principal components and sabkha index 36 point were correctly classified as being sabkha while 4 point were misclassified. This represented a significant improvement in mapping and identifying sabkha pixels from other land cover types.

\section{Conclusions}

A new approach towards mapping and identifying sabkha areas is presented in this research. The new methodology uses, in addition to the multispectral data, transformed multispectral data from principal component analysis and a sabkha index. This improved dataset produced higher levels of accuracy in mapping sabkha in comparison to only using multispectral data. Accurate mapping and identifying sabkha areas is an important step for mapping the environmental change in sabkha habitats. This work will be further improved by using much finer spatial resolution data. This is expected to improve the accuracy as inland sabkha areas, while are scattered in larger areas, are generally smaller in size.

\section{References}

[1] G. Evans, V. Schmidt, P. Bush, and H. Nelson, "Stratigraphy and geologic history of the sabkha abu dhabi, persian gulf," Sedimentology, Article vol. 12, no. 1/2, p. 145, 1969.

[2] C. F. Pain and M. A. Abdelfattah, "Landform evolution in the arid northern United Arab Emirates: Impacts of tectonics, sea level changes and climate," CATENA, vol. 134, pp. 14-29, 11// 2015.

[3] E. A. Shinn, "Tidal flat environment," in Carbonate depositional environments, vol. 33: American Association of Petroleum Geologists Tulsa, 1983, pp. 171-210.

[4] A. Allbed and L. Kumar, "Soil salinity mapping and monitoring in arid and semi-arid regions using remote sensing technology: a review," Advances in remote sensing, vol. 2013, 2013.

[5] H. Raafat, "Climate," ed. Physical Geography Sector Paper, Environment Agency Abu Dhabi, 2007, pp. 72-89.

[6] P. Paul, A. K. Al Tenaiji, and N. Braimah, "A review of the water and energy sectors and the use of a nexus approach in Abu Dhabi," International journal of environmental research and public health, vol. 13, no. 4, p. 364, 2016.

[7] R. G. C. Bathurst, "Carbonate sediments and their diagenesis," Developments in Sedimentology, vol. 12, 1975.

[8] A. S. Alsharhan and C. G. S. C. Kendall, "Holocene coastal carbonates and evaporites of the southern Arabian Gulf and their ancient analogues," Earth-Science Reviews, vol. 61, no. 3-4, pp. 191-243, 6// 2003.

[9] S. W. Lokier, A. Knaf, and S. Kimiagar, "A quantitative analysis of Recent arid coastal sedimentary facies from the Arabian Gulf Coastline of Abu Dhabi, United Arab Emirates," Marine Geology, vol. 346, pp. 141-152, 12/1/2013.

[10] T. Stevens, M. J. Jestico, G. Evans, and A. Kirkham, "Eustatic control of late Quaternary sea-level change in the Arabian/Persian Gulf," Quaternary Research, vol. 82, no. 1, pp. 175-184, 7// 2014.

[11] P. Kassler, "The structural and geomorphic evolution of the Persian Gulf," in The Persian Gulf: Springer, 1973, pp. 11-32.

[12] R. Weijermars, "Quaternary evolution of Dawhat Zulum (half moon bay) region eastern province, Saudi 
Arabia," GeoArabia, vol. 4, no. 1, pp. 71-90, 1999.

[13] A. Al-Hurban and I. Gharib, "Geomorphological and sedimentological characteristics of coastal and inland sabkha, Southern Kuwait," Journal of arid environments, vol. 58, no. 1, pp. 59-85, 2004.

[14] A. Al-Farraj, "An evolutionary model for sabkha development on the north coast of the UAE," Journal of Arid Environments, vol. 63, no. 4, pp. 740-755, 12// 2005.

[15] H. S. Edgell, "Sources of sand for Arabian sand dune deserts," Arabian Deserts: Nature, Origin, and Evolution, pp. 239-261, 2006.

[16] G. Brown, "The sabkha vegetation of the United Arab Emirates," in Sabkha Ecosystems: Volume II: West and Central Asia, M. A. Khan, B. Böer, G. S. Kust, and H.-J. Barth, Eds. Dordrecht: Springer Netherlands, 2006, pp. 37-51.

[17] A. A. Al-Jaloud and G. Hussain, "Sabkha ecosystem and halophyte plant communities in Saudi Arabia," in Sabkha ecosystems: Springer, 2006, pp. 1-7.

[18] D. Ravi Shankar, K. Ramana Venkata, and S. Amarendra Narayana, "Generation of Farm-Level Information on Salt-Affected Soils Using IKONOS-II Multispectral Data," in Remote Sensing of Soil Salinization: CRC Press, 2008.

[19] B. Mougenot, M. Pouget, and G. F. Epema, "Remote sensing of salt affected soils," Remote Sensing Reviews, vol. 7, no. 3-4, pp. 241-259, 1993.

[20] A. Sadiq and F. Howari, "Remote Sensing and Spectral Characteristics of Desert Sand from Qatar Peninsula, Arabian/Persian Gulf," Remote Sensing, Article vol. 1, no. 4, pp. 915-933, 2009.

[21] R. Katawatin and W. Kotrapat, "Use of LANDSAT-7 ETM+ with ancillary data for soil salinity mapping in Northeast Thailand," pp. 708-716: International Society for Optics and Photonics.

[22] A. E. K. Douaoui, H. Nicolas, and C. Walter, "Detecting salinity hazards within a semiarid context by means of combining soil and remote-sensing data," Geoderma, vol. 134, no. 1, pp. 217-230, 2006.

\section{Authors' Profiles}

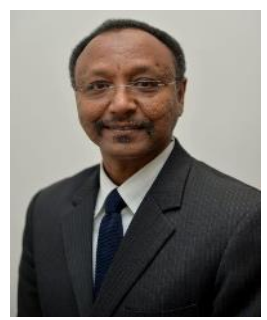

Dr. Abuelgasim received both his masters and $\mathrm{PhD}$ degrees from Boston University in 1996. Following he worked for one year as an assistant professor of remote sensing and surveying at Sultan Qabous University in Oman with the department of civil engineering. He later joined the NASA Goddard Space Flight Center in Maryland, USA in 1998 as a visiting scientist where he worked in a research program exploiting multi-angle remote sensing observations. In 2000 he joined the Canada Centre for Remote Sensing and the Canadian Space Agency as a research scientist. Dr Abuelgasim also served as the international geospatial data and remote sensing consultant during 2012 for the Nile Basin Initiative. Dr Abuelgasim is currently an assistant professor at the United Arab Emirates University and his research and teaching interests are focused on the analysis of geospatial data for information products generation, physical and human geography, hydrology, and on the effects of human induced environmental and ecological changes.

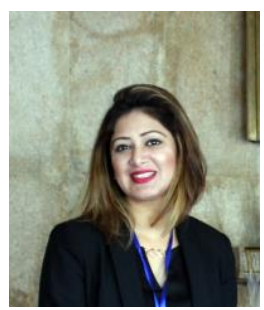

Rubab Ammad is a final year student of Masters in Environmental Sciences at UAE university with her bachelors degree in geophysics. She is currently involved in research projects related soil salinity interpretation using satellite data, with special interest in Sabkha of UAE, and waste water treatment. Besides academia, she has three years' experience in Oil and Gas industry as an exploration geophysicist. 
How to cite this paper: Abdelgadir Abuelgasim, Rubab Ammad,"Mapping Sabkha Land Surfaces in the United Arab Emirates (UAE) using Landsat 8 Data, Principal Component Analysis and Soil Salinity Information", International Journal of Engineering and Manufacturing(IJEM), Vol.7, No.4, pp.1-11, 2017.DOI: 10.5815/ijem.2017.04.01 